\title{
Differences in the effects of vasopressin and oxytocin on rabbit myometrial activity and a possible mediation of prostaglandins
}

\author{
T. Laudański*, M. Åkerlund and S. Batra \\ Department of Obstetrics and Gynecology, University of Lund, Lund, Sweden
}

\begin{abstract}
Summary. Uterine responses to vasopressin and oxytocin were monitored in nonpregnant and 3- or 6-8-day-pregnant rabbits by recording the intrauterine pressure. Oxytocin stimulated uterine activity in all groups, but the effect of vasopressin was stimulatory in non-pregnant animals, inhibitory in those 3 days post coitum and weakly stimulatory in those later in pregnancy. Inhibition of prostaglandin (PG) synthesis, by the administration of indomethacin, reduced the spontaneous uterine activity as well as the responses to oxytocin and vasopressin in the non-pregnant rabbits, but had little effect in the pregnant animals. During infusion of PGF-2 $\alpha$, PGE-1 or PGE-2 in 6-8-day-pregnant rabbits, the stimulatory response to vasopressin, although slight before the infusion, was inhibited whereas the stimulatory response to oxytocin remained virtually unchanged. The results suggest that vasopressin and oxytocin, under certain hormonal conditions, are able to activate the uterine contractions by mechanisms in which the involvement of PG is not obligatory.
\end{abstract}

\section{Introduction}

It is well established that the uterine sensitivity to various stimulants is greatly influenced by the extent of the pre-exposure to ovarian steroids. However, maximal sensitivity to different stimulants may not occur at the same endocrine state. A difference in the stimulatory effects of the two posterior pituitary hormones, vasopressin and oxytocin, has in fact been observed in the human uterus (Bengtsson, 1973). It therefore seems possible that even closely related agents may act on the uterine smooth muscle through different mechanisms.

It has been suggested that all myometrial stimulants manifest their action by the production or liberation of prostaglandins (PG) (Csapo \& Csapo, 1974; see also Batra \& Bengtsson, 1976). The present study was designed to examine further the uterine sensitivity to vasopressin and oxytocin at different endocrine conditions and to investigate the extent to which the difference in the effect of the two polypeptides can be explained by a mechanism involving PGs.

\section{Materials and Methods}

A total of 25 rabbits of the Swedish Land race, weighing about $3 \mathrm{~kg}$, were used: 15 were non-pregnant and pregnant does were investigated at 3 ( 3 does) or 6-8 ( 7 does) days post coitum. The gestational state of the rabbits was confirmed by examination of the ovaries and the uterus at laparotomy and by radioimmunoassay of progesterone in plasma (Batra, 1976). The mean progesterone level was $4.38 \pm 1.23$ (S.E.M.) $\mathrm{ng} / \mathrm{ml}$ in the pregnant animals and $0.30 \pm 0.04 \mathrm{ng} / \mathrm{ml}$ in the non-pregnant does.

\section{Experimental procedure}

The rabbits were anaesthetized by intravenous pentobarbitone sodium (Mebumalnatrium 6\%: ACO, Sweden) given into a marginal ear vein. The abdomen was opened by a lower medial incision not exceeding $5 \mathrm{~cm}$ in length. For intrauterine pressure recordings, a microtransducer catheter

\footnotetext{
- Present address: Institute of Obstetrics and Gynecology, Medical School in Bialystok, Poland.
} 
(Model PC 470; Millar Instruments, Houston, Texas, U.S.A.) (Åkerlund, Bengtsson \& Ulmsten, 1976) was inserted through a small incision at the ovarian end of the right uterine horn and the sensor of the catheter was placed in the middle part of that horn. The pressure transducer was connected to an amplifier (EMT-311: Elema-Siemens, Stockholm, Sweden) and a potentiometer recorder (Omniscribe; Houston Instruments, Texas, U.S.A.). The abdomen was sutured leaving a thermometer for continuous monitoring of the body temperature. The arterial blood pressure was monitored by an open-ended saline-filled polyethylene catheter (i.d. $0.5 \mathrm{~mm}$, o.d. $0.9 \mathrm{~mm}$ ) introduced into a femoral artery. The catheter was connected to a pressure transducer (EMT-34; Elema-Siemens), which was also combined with the potentiometer recorder via an amplifier (EMT-311: Elema-Siemens). A vinyl catheter (i.d. $0.5 \mathrm{~mm}$, o.d. $0.9 \mathrm{~mm}$ ) was introduced into a femoral vein. All drugs were given through this catheter, either in single injection or in constant infusion by the aid of an infusion pump. Throughout the recording session the animals were under light anaesthesia which was achieved by injection of small doses of anaesthetic (1-2 mg) when needed. The body temperature of the rabbit during the surgical procedure was maintained at a constant level between 37.0 and $37.5^{\circ} \mathrm{C}$ by an electric blanket underneath the animal. Heating was usually not necessary during the recording session. The recordings lasted between 10 and $14 \mathrm{~h}$, during which a rabbit received a total of approximately $25 \mathrm{ml}$ fluid intravenously. The effects of vasopressin and oxytocin were investigated without any previous drug treatment, after blocking the endogenous synthesis of PGs by indomethacin (Smith, Temple \& Shearman, 1975), and during constant infusion of PGF-2 $\alpha$, PGE-1 or PGE-2.

The following drugs were used: arginine vasopressin (Ferring, Sweden), oxytocin (Syntocinon: I.C.I., England), indomethacin sulphate (Dumex, Denmark), PGF-2 $\alpha$ (Amoglandin: Astra, Sweden). PGE-1 and PGE-2 (Upjohn, U.S.A.). Arginine vasopressin, indomethacin and the PGs were gifts from the producers.

\section{Results}

These are summarized in Table 1.

Table 1. Effects of vasopressin and oxytocin on the uterine activity in rabbits

\begin{tabular}{|c|c|c|c|c|c|c|}
\hline & & & \multicolumn{4}{|c|}{ Pregnant } \\
\hline & \multicolumn{2}{|c|}{$\begin{array}{c}\text { Non-pregnant } \\
(\mathrm{N}=15)^{*}\end{array}$} & \multicolumn{2}{|c|}{$\begin{array}{c}3 \text { days } \\
(\mathrm{N}=3) \dagger\end{array}$} & \multicolumn{2}{|c|}{$\begin{array}{l}6-8 \text { days } \\
(N=7) \ddagger\end{array}$} \\
\hline & Vasopressin & Oxytocin & Vasopressin & Oxytocin & Vasopressin & Oxytocin \\
\hline $\begin{array}{l}\text { Without pretreatment } \\
\text { After indomethacin } \\
\text { During PG infusion }\end{array}$ & $\begin{array}{l}+ \\
(+) \\
(+)\end{array}$ & $\begin{array}{l}(+) \\
(+) \\
(+)\end{array}$ & $\begin{array}{l}- \\
- \\
-\end{array}$ & $\begin{array}{l}+ \\
+ \\
+\end{array}$ & $\begin{array}{l}(+) \\
(+) \\
-\end{array}$ & $\begin{array}{l}+ \\
+ \\
+\end{array}$ \\
\hline
\end{tabular}

+ , strong stimulation; $(+)$, weak or insignificant stimulation; - , strong inhibition; $(-)$, weak or insignificant inhibition.

* All animals responded to oxytocin and vasopressin when there was no pretreatment, whereas 12 responded after indomethacin treatment and 13 during PG infusion.

$\dagger$ All animals responded to all treatments.

$\ddagger$ All animals responded to vasopressin and oxytocin when there was no pretreatment; 6 did so after indomethacin treatment and during PG infusion.

\section{Spontaneous activity}

In the non-pregnant rabbits, contractions were generally regular with a frequency of 40-70 contractions/h, an amplitude of 5-20 mmHg and a duration of 15-20 sec (Text-fig. 1). In the pregnant animals, however, the contractions were more irregular and more frequent (Text-figs 2-5). The pattern of contractile activity changed slightly when the anaesthetic was administered: the uterine activity was usually slightly inhibited and the arterial blood pressure decreased for up to $5 \mathrm{~min}$ after the injection. 


\section{Effects of vasopressin and oxytocin}

Without pretreatment. Vasopressin and oxytocin in doses of 0.05 i.u. elicited a clear response in most of the rabbits. With a higher dose ( 0.15 i.u.) of either drug, the response was generally more pronounced (Text-figs 2-4). In the non-pregnant rabbits vasopressin increased the contractile activity both in terms of amplitude and frequency of the contractions, as well as the uterine tone (Text-fig. 1). In the pregnant rabbits the response to vasopressin differed with the stage of gestation. In all 3 rabbits investigated at 3 days post coitum, uterine activity was initially inhibited (Text-fig. 4) and then increased after about $5 \mathrm{~min}$. At 6-8 days of pregnancy vasopressin had no or

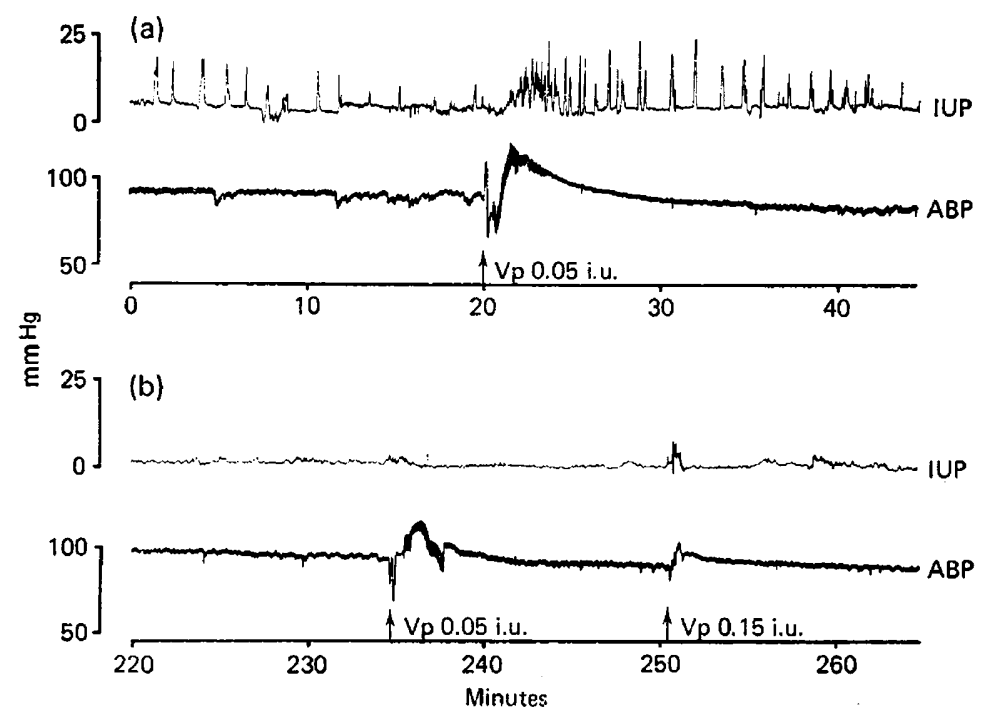

Text-fig. 1. Effects of i.v. injections of arginine vasopressin (VP) on intrauterine pressure (IUP) and arterial blood pressure (ABP) in a non-pregnant rabbit (a) before and (b) $2 \mathrm{~h}$ after treatment with $20 \mathrm{mg}$ indomethacin.

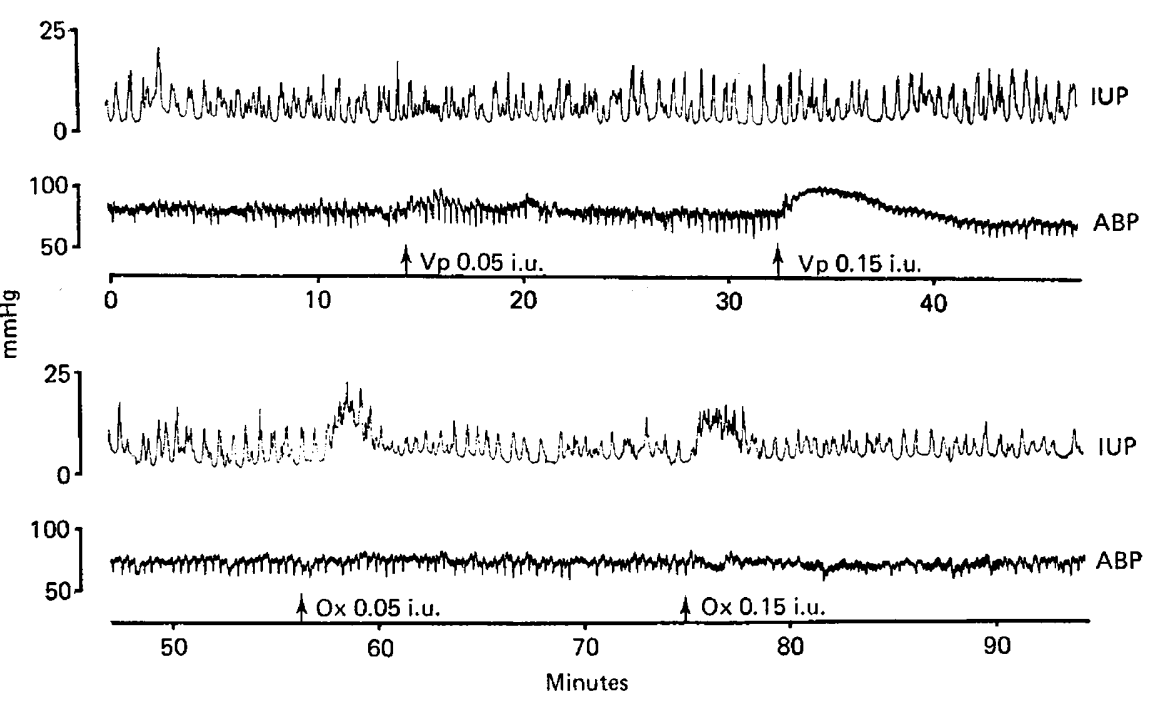

Text-fig. 2. Comparison of the effects of i.v. injections of arginine vasopressin (Vp) and oxytocin (Ox) on intrauterine pressure (IUP) and arterial blood pressure (ABP) in an 8-day-pregnant rabbit. 


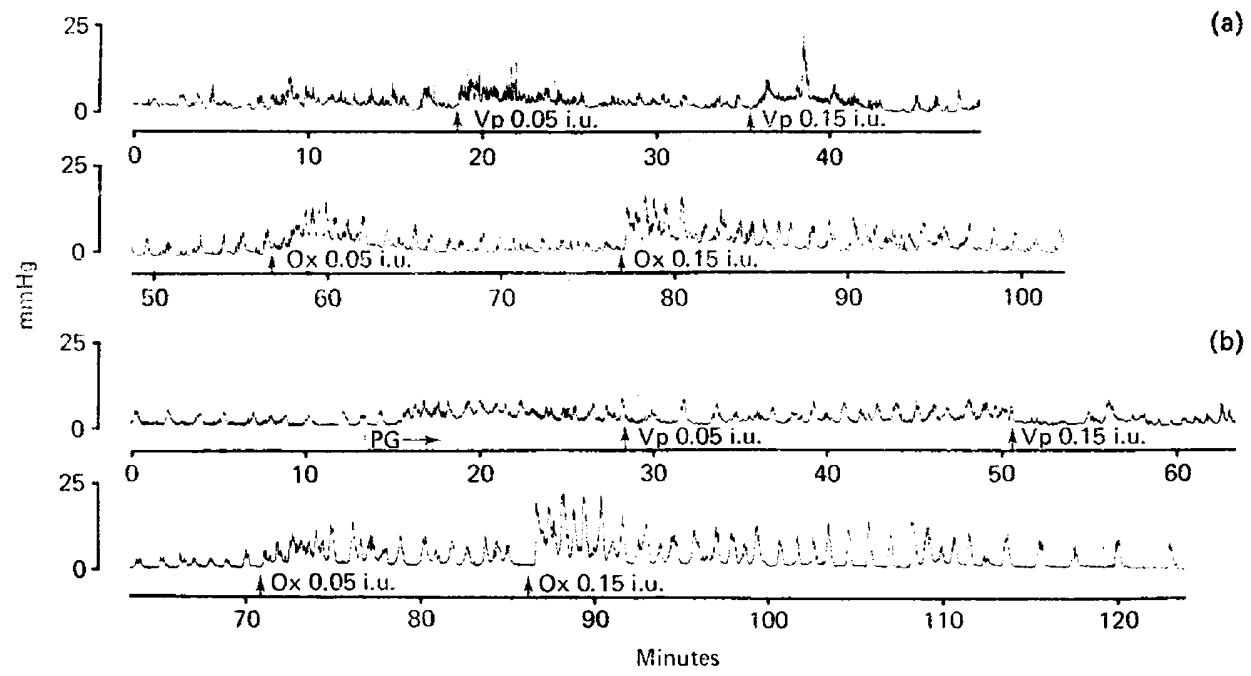

Text-fig. 3. The effect on intrauterine pressure in an 8-day pregnant rabbit (same animal as that in Text-fig. 2) of i.v. injections of arginine vasopressin (VP) and oxytocin (Ox) (a) after pretreatment with indomethacin and (b) during infusion of PGF-2a (5 $\mu \mathrm{g} / \mathrm{min})$.

only a slight stimulatory effect on the uterine activity. Oxytocin in the same doses had a stimulatory effect in all three groups of rabbits, although the response seemed to be more pronounced in the pregnant than in the non-pregnant animals. The arterial blood pressure increased after injection of vasopressin in all rabbits, whereas the effect of oxytocin was inconsistent (Text-figs 1 and 2).

After indomethacin. A gradual but clear decrease in spontaneous uterine activity was observed in non-pregnant animals after administration of $20 \mathrm{mg}$ indomethacin (Text-fig. 1), whereas in the pregnant animals the inhibitory effect was less pronounced (Text-figs 2 and 3 ). The effect of indomethacin on the arterial blood pressure was negligible. Indomethacin did not qualitatively change the uterine effect of the polypeptides (Text-figs 1 and 2), although the magnitude of the response in the non-pregnant rabbits decreased (Text-fig. 1).

During $P G$ infusion. There was a difference in the uterine response to $P G$ s given as single injections $(5-90 \mu g)$. PGF-2 $\alpha$ generally stimulated the uterine activity and increased the arterial blood pressure, whereas PGE-1 and PGE-2 caused an initial decrease in both the uterine activity and the arterial blood pressure and then an increase after about 5 min (Text-fig. 5). However, when any of the PGs

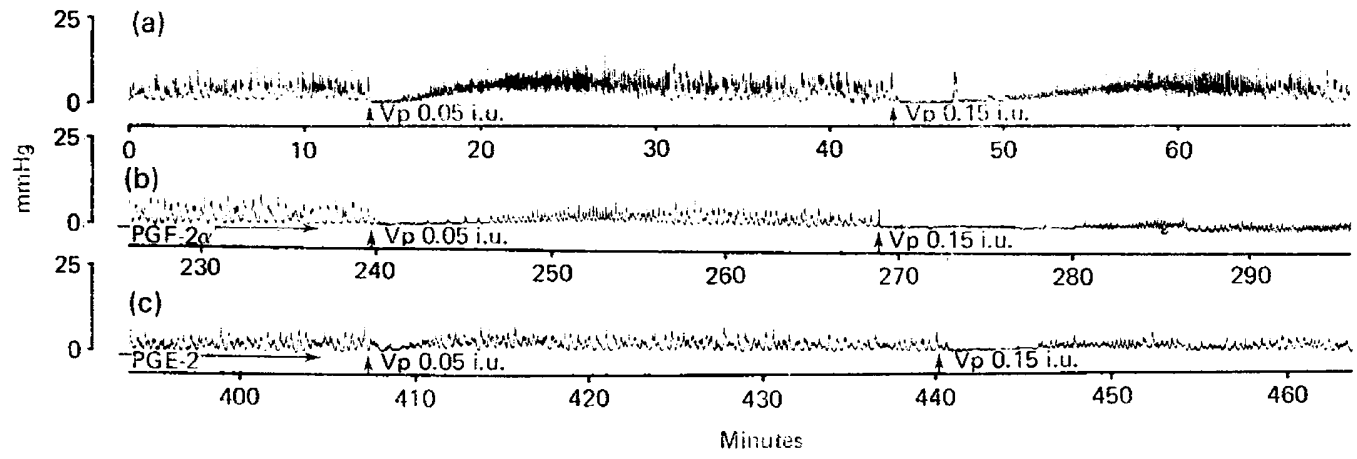

Text-fig. 4. Effect, measured by intrauterine pressure, of i.v. injections of arginine vasopressin (Vp) on (a) spontaneous uterine activity, and the activity during constant infusion of (b) PGF-2 $\alpha(5 \mu \mathrm{g} / \mathrm{min})$ and (c) PGE-2 $(5 \mu \mathrm{g} / \mathrm{min})$ in a 3-day-pregnant rabbit. 


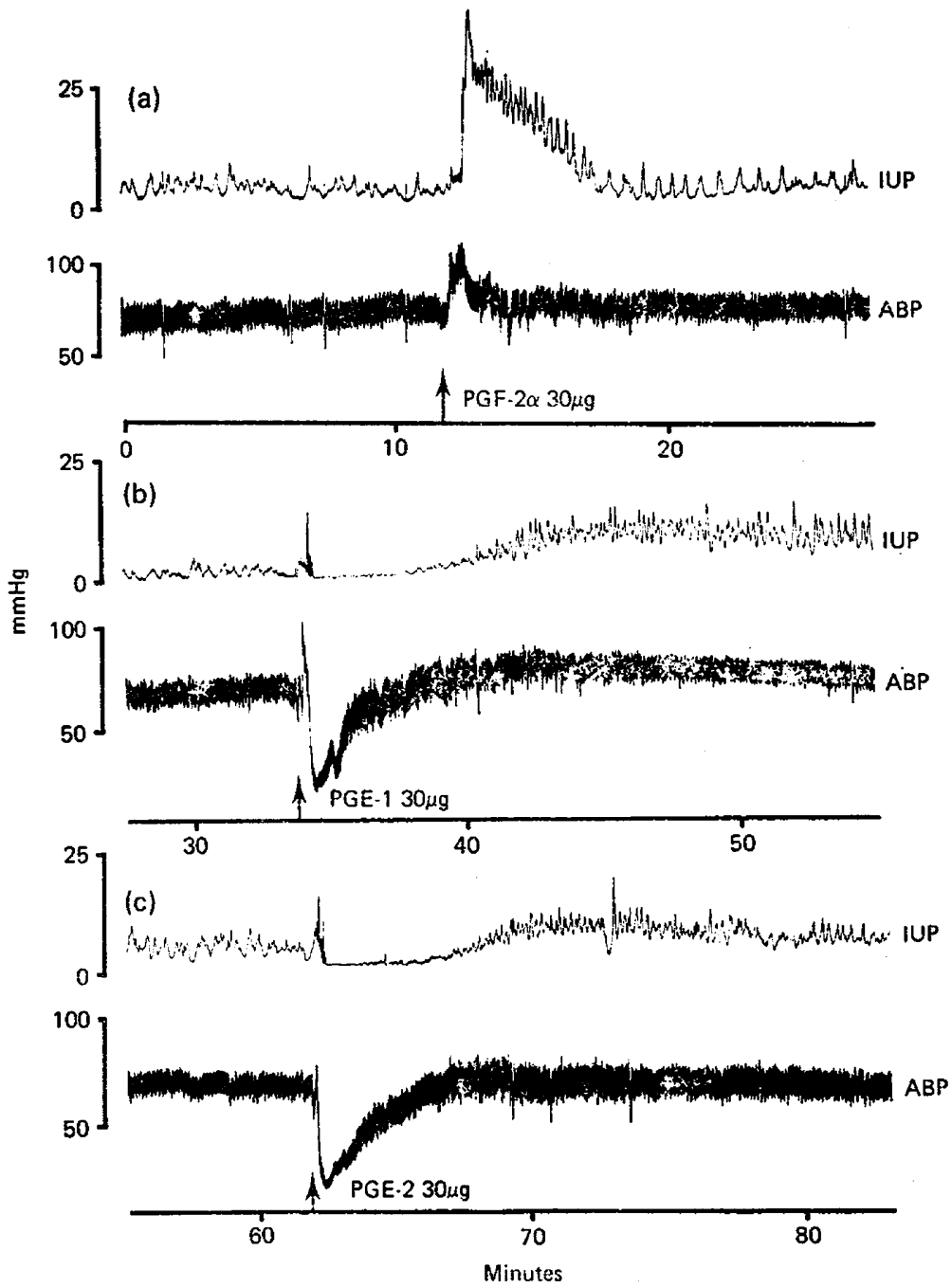

Text-fig. 5. Effect of single i.v. injections of (a) PGF-2 $\alpha$, (b) PGE-1 and (c) PGE-2 on intrauterine pressure (IUP) and arterial blood pressure (ABP) in a 6-day-pregnant rabbit.

were constantly infused ( $5 \mu \mathrm{g} / \mathrm{min}$ ), the uterine activity was stimulated (Text-fig. 3). In the 6-8-daypregnant rabbits, vasopressin given during a constant infusion of any of the PGs inhibited the contractile activity (Text-fig. 3), irrespective of whether indomethacin had been given previously. In the non-pregnant and 3-day-pregnant animals the effect of vasopressin during PG infusion remained unchanged (Text-fig. 4). In all rabbits the stimulatory response to oxytocin was retained when given during the infusions of $\mathrm{PG}$.

\section{Discussion}

The present results clearly confirm that vasopressin and oxytocin differ in their effects on myometrial activity in rabbits and that, under certain conditions, these posterior pituitary hormones can have opposite effects on the contractile response. The uterine sensitivity, especially to vasopressin, differed markedly with the endocrine condition of the rabbits in the present study. 
Vasopressin and PGs given in single injections caused significant changes in arterial blood pressure in some recordings (Text-figs 1 and 5) and it can be argued that the changes in uterine activity seen after administration of these substances were due to their effects on the uterine blood flow. However, Akerlund \& Andersson (1976) have shown that in non-pregnant women the changes in myometrial activity after treatment with vasopressin generally preceded the changes in blood flow. When PGs were given as constant infusions during the present study (Text-figs 3 and 4) they caused no significant changes in arterial blood pressure although the myometrial activity increased slightly. After injection of a relatively large dose of PGE-1 or PGE-2 (Text-fig. 5) there was inhibition of myometrial activity, presumably because of their general cardiovascular effect, but after this brief period the blood pressure returned to control levels and the myometrial activity increased significantly.

In the present study the differences between the effects of vasopressin and oxytocin became even more evident during constant PG infusion. The slight stimulatory effect of vasopressin, observed before the infusion of PG in the 6-8-day-pregnant rabbits, changed to inhibition while the stimulatory response to oxytocin remained practically unchanged. This finding suggests that there are differences between vasopressin and oxytocin in their interaction with PG. There are no reports in the literature on a possible interaction between vasopressin and PG in their effect on the uterus, and only limited data on a possible interrelationship between oxytocin and PG in vivo have been published (Mitchell, Flint \& Turnbull, 1975). Myometrial strips from the pregnant human uterus contracted when exposed to subthreshold doses of oxytocin in the presence of PG (Brummer, 1971). Vane \& Williams (1973), studying the isolated uterus of non-pregnant rats, found that oxytocin-induced contractions were abolished when indomethacin was added to the bathing fluid but that indomethacin had no effect on the contractile activity of uteri stimulated with PGF-2 $\alpha$. Hertelendy (1973) has shown that indomethacin will prevent oxytocin-induced parturition in rabbits by blocking uterine contractions, suggesting that uterine PG synthesis is essential for the action of oxytocin at term. These observations, together with the present findings suggest that the involvement of PG in the mediation of oxytocin effects might be more important at term than in early pregnancy.

Csapo \& Csapo (1974) have proposed that a PG step may represent a 'bottle-neck' in mechanisms of myometrial activation, irrespective of the nature of the stimulus. In the present study both the spontaneous uterine activity and the response to vasopressin or oxytocin clearly diminished in the non-pregnant rabbits after treatment with indomethacin, but was unaltered in the pregnant animals. In has been shown that the capacity of the rat uterus for synthesis of endogenous PGs can differ at different stages of gestation (Williams, Sneddon \& Harrey, 1974). However, it would be expected that a practically complete inhibition of PG synthesis with the relatively high dose of indomethacin used in the present study was achieved in the pregnant and non-pregnant animals. Our results suggest therefore that vasopressin and oxytocin are able to activate the uterus through mechanisms in which the involvement of PG is not obligatory, at least in the pregnant rabbits. Support for this view is provided by the findings that indomethacin inhibited the oxytocin-induced release of PGF- $2 \alpha$ in sheep, but did not prevent the oxytocin-induced uterine contractions (Roberts, Barcikowski, Wilson, Skarnes \& McCracken, 1975) and that there is a synergism between oxytocin and PG in the induction of labour or abortion, without an increase in the side effects of PG (Embrey, 1971).

Uterine stimulants might therefore act independently of PG in addition to an action mediated by PG. Which of these two modes of actions predominates could be determined by the endocrine state of the uterus, in view of the fact that the synthesis and release of PG are known to be influenced by the hormonal conditions (Blatchley et al., 1971; Demers, Yoshinaga \& Greep, 1974; Ham, Cirillo, Zanetti \& Kuehl, 1975).

We are most grateful to Professor Lars Philip Bengtsson for his valuable criticism, advice and encouragement. This study was supported by the Ford Foundation and the Swedish Medical Research Council (project No. 4781). T.L. and M. . are grateful to AB Ferring, and Förenade Liv (Sweden) respectively for fellowships. 


\section{References}

ÅKerLUND, M. \& ANDERsson, K.E. (1976) Vasopressin response and terbutaline inhibition of the uterus. Obstet. Gynec., N.Y. 48, 528-536.

Ákerlund, M., Bengtsson, L.Ph. \& Ulmsten, U. (1976) Recording of myometrial activity in the nonpregnant human uterus by a micro-transducer catheter. Biophys. Reprod. (in press).

Batra, S. (1976) New simplified procedures for the determination of progesterone by competitive protein binding and radioimmunoassay. $J$. Steroid Biochem. 7, 131-134.

Batra, S. \& Bengtsson, L.Ph. (1976) Mechanism for increased production of prostaglandins in labour. Lancet i, 1164-1165.

Bengtsson, L.Ph. (1973) Hormonal effects on human myometrial activity. Vitams Horm. 31, 257-303.

Blatchley, F.R., Donovan, B.T., Poyser, N.L., Horton, E.W., Thompson, C.J. \& Los, M. (1971) Identification of prostaglandin $F_{2 \alpha}$ in the uteroovarian blood of guinea-pig after treatment with oestrogen. Nature, Lond. 230, 243-244.

BRUMMER, H.C. (1971) Interaction of E prostaglandins and syntocinon on the pregnant human myometrium. J. Obstet. Gynaec. Br. Commonw. 78, 305-309.

CSAPO, A.I. \& CSAPO, E.E. (1974) The "prostaglandin step", a bottleneck in the activation of the uterus. Life Sci. 14, 719-724.

Demers, L.M., Yoshinaga, K. \& Greep, R.O. (1974) Prostaglandin $\mathrm{F}$ in monkey uterine fluid during the menstrual cycle and following steroid treatment. Prostaglandins 5, 513-519.
EmbreY, M. (1971) PGE compounds for induction of labour and abortion. Ann. N.Y. Acad. Sci. 180, 518-523.

ham, E.A., Cirillo, V.J., Zanetti, M.E. \& Kuehl, F.A., JR (1975) Estrogen-directed synthesis of specific prostaglandins in uterus. Proc. natn. Acad. Sci. U.S.A. 72, 1420-1424.

HeRTelendy, F. (1973) Block of oxytocin-induced parturition and oviposition by prostaglandin inhibitors. Life Sci. 13, 1581-1589.

Mitchell, M.D., Flint, A.P.F. \& Turnbull, A.C. (1975) Stimulation by oxytocin of prostaglandin F levels in uterine venous effluent in pregnant and puerperal sheep. Prostaglandins 9, 47-55.

Roberts, J.S., Barcikowski, B., Wilson, L., SKarnes, R.C. \& MCCracken, J.A. (1975) Hormonal and related factors affecting the release of prostaglandin $F_{2 \alpha}$ from the uterus. J. Steroid Biochem. 6, 10911097.

Smith, I.O., Temple, D.M. \& Shearman, R.P. (1975) The antagonism by anti-inflammatory analgesics of prostaglandin $F_{2 a}$-induced contractions of human and rabbit myometrium in vitro. Prostaglandins 10, 41-57.

Vane, J.R. \& Williams, K.I. (1973) Prostaglandin production contributes to the contractions of rat isolated uterus. Br.J. Pharmacol. 45, 146P.

Williams, K.I., SNeddon, J.M. \& HarRey, P.J. (1974) Prostaglandin production by the pregnant rat uterus in vitro and its relevance to parturition. Pol. J. Pharmacol. Pharm. 26, 207-215.

Received 18 January 1977 